\title{
Acute effects of combined exercise and oscillatory positive expiratory pressure therapy on sputum properties and lung diffusing capacity in cystic fibrosis: a randomized, controlled, crossover trial
}

Thomas Radtke ${ }^{1,2^{*}}$, Lukas Böni ${ }^{3}$, Peter Bohnacker ${ }^{3}$, Marion Maggi-Beba ${ }^{2}$, Peter Fischer ${ }^{3}$, Susi Kriemler ${ }^{1}$, Christian Benden ${ }^{4}$ and Holger Dressel ${ }^{2}$

\begin{abstract}
Background: Regular airway clearance by chest physiotherapy and/or exercise is critical to lung health in cystic fibrosis (CF). Combination of cycling exercise and chest physiotherapy using the Flutter ${ }^{\circledast}$ device on sputum properties has not yet been investigated.

Methods: This prospective, randomized crossover study compared a single bout of continuous cycling exercise at moderate intensity (experiment A, control condition) vs a combination of interval cycling exercise plus Flutter ${ }^{\circledR}$ (experiment B). Sputum properties (viscoelasticity, yield stress, solids content, spinnability, and ease of sputum expectoration), pulmonary diffusing capacity for nitric oxide (DLNO) and carbon monoxide (DLCO) were assessed at rest, directly and 45 min post-exercise (recovery) at 2 consecutive visits. Primary outcome was change in sputum viscoelasticity (G', storage modulus; G", loss modulus) over a broad frequency range (0.1-100 rad. $\mathrm{s}^{-1}$ ).

Results: 15 adults with CF (FEV 1 range 24-94\% predicted) completed all experiments. No consistent differences between experiments were observed for $G^{\prime}$ and $G^{\prime \prime}$ and other sputum properties, except for ease of sputum expectoration during recovery favoring experiment $A$. $D L N O, D L C O$, alveolar volume $\left(V_{A}\right)$ and pulmonary capillary blood volume $\left(V_{\text {cap }}\right)$ increased during experiment $A$, while $D L C O$ and $V_{\text {cap }}$ increased during experiment $B(a l l ~ P<0.05)$. We found no differences in absolute changes in pulmonary diffusing capacity and its components between experiments, except a higher $V_{A}$ immediately post-exercise favoring experiment $A(P=0.032)$.
\end{abstract}

Conclusions: The additional use of the Flutter ${ }^{\circledR}$ to moderate intensity interval cycling exercise has no measurable effect on the viscoelastic properties of sputum compared to moderate intensity continuous cycling alone. Elevations in diffusing capacity represent an acute exercise-induced effect not sustained post-exercise.

Trial registration: ClinicalTrials.gov; No.: NCT02750722; URL: clinical.trials.gov; Registration date: April 25th, 2016.

Keywords: Lung disease, Sputum viscoelasticity, Diffusing capacity for nitric oxide, Exercise, Airway clearance, Mucus

\footnotetext{
*Correspondence: thomas.radtke@uzh.ch

${ }^{1}$ Epidemiology, Biostatistics and Prevention Institute (EBPI), University of

Zurich, Zurich, Switzerland

${ }^{2}$ Division of Occupational and Environmental Medicine, University of Zurich

and University Hospital Zurich, Zurich, Switzerland

Full list of author information is available at the end of the article
}

(c) The Author(s). 2018 Open Access This article is distributed under the terms of the Creative Commons Attribution 4.0 International License (http://creativecommons.org/licenses/by/4.0/), which permits unrestricted use, distribution, and reproduction in any medium, provided you give appropriate credit to the original author(s) and the source, provide a link to the Creative Commons license, and indicate if changes were made. The Creative Commons Public Domain Dedication waiver (http://creativecommons.org/publicdomain/zero/1.0/) applies to the data made available in this article, unless otherwise stated. 


\section{Background}

Cystic fibrosis (CF) is the most common genetic life-limiting disease in Caucasians caused by abnormalities in CF conductance transmembrane protein function. Depletion of airway surface liquid, dehydrated mucus, chronic inflammation and infection contribute to accumulation of secretions and subsequent progressive lung damage in CF [1]. Regular airway clearance is therefore of critical importance to lung health in CF. Exercise and chest physiotherapy are accepted airway clearance techniques (ACT's) in $\mathrm{CF}$, belonging to the current top ten research priorities [2]. There are a number of different ACT's such as the active cycle of breathing technique, high-frequency chest wall oscillations, positive expiratory pressure (PEP) and oscillatory PEP. Oscillatory PEP with the Flutter ${ }^{\circ}$ is equally effective compared to other ACT's [3] and has been shown to favorably alter respiratory flow [4], to increase sputum expectoration [5] and to reduce sputum viscoelasticity $[6,7]$ in CF.

Exercise alone or in combination with chest physiotherapy improves airway clearance and sputum expectoration $[6,8]$, but the exact mechanisms are not fully understood. Moreover, acute exercise is thought to facilitate mucociliary clearance by increased shear stress on airway epithelium and ciliary beat frequency as a result of an increased ventilation [9], improved water content of mucus [10] and increased trunk oscillations during weight bearing exercises such as walking or running [11]. Recently, moderate intensity exercise has been identified as 'optimal training intensity' for individuals with mild to moderate CF lung disease due to improvements in bronchodilation and pulmonary diffusing capacity and prevention of airflow restriction compared to vigorously intense exercise [12]. Enhanced mucus clearance might potentially (at least in part) result in an improvement in pulmonary gas diffusion.

The aim of this study was to compare a single bout of moderate intensity cycling exercise incorporating a breathing therapy device, the Flutter ${ }^{\bullet}$, with a single bout of moderate intensity cycling exercise alone on sputum viscoelasticity (primary endpoint) and pulmonary diffusing capacity in adults with CF. We hypothesized that the combination of a high ventilation during cycling exercise in combination with increased oscillatory shear stress (Flutter ${ }^{\oplus}$ ) yields greater improvements in sputum viscoelasticity compared to cycling exercise alone.

\section{Methods}

\section{Study design}

We conducted a prospective, randomized, controlled crossover trial (Clinicaltrials.gov, NCT02750722). Adults with CF were invited to our laboratory facility on three different occasions. At the first study visit, the patients provided a sputum sample, performed pulmonary function testing and cardiopulmonary exercise testing (CPET). At the second and third study visit, patients provided sputum samples, performed pulmonary function testing and, depending on randomization, performed either continuous cycling exercise at moderate intensity without Flutter $^{\oplus}$ (Experiment A, control condition) or moderate intensity interval cycling exercise incorporating Flutter ${ }^{\bullet}$ therapy (Experiment B, experimental condition). The detailed exercise protocol including measurements and assessments during study visit 2 and 3 are shown in Fig. 1.

\section{Study participants}

Individuals with $\mathrm{CF}$ were recruited from the Adult $\mathrm{CF}$ Center at the University Hospital Zurich, Switzerland, between June 2016 and January 2017. Patients aged 18 years and older with a confirmed diagnosis of CF able to provide sputum samples were included. Exclusion criteria were as follows: i) listing for lung transplantation or status post lung transplantation, ii) chronic pulmonary infection with Burkholderia cepacia complex, iii) unstable clinical condition (i.e., major hemoptysis or pneumothorax within the last 3 months, acute pulmonary exacerbation [13], intravenous antibiotic treatment during the last 4 weeks, change in pulmonary medication during the study period); iv) cardiac arrhythmias with exercise and v) requirement of additional oxygen with exercise. Ethical approval was obtained from the Cantonal Ethics Committee of Zurich (2015-00153), Switzerland. All patients provided written informed consent.

\section{Randomization}

We used central randomization to randomly allocate patients to the different experimental conditions (Experiment A or B). A person not involved in the study generated a list of random numbers using the statistical software package STATA (Version 12, StataCorp. 2012, College Station, Texas, USA). The list consisted of 30 random numbers, where even numbers represented the experimental condition ' $\mathrm{A}$ ' and odd numbers the condition ' $\mathrm{B}$ '. The order of the experiments at study visit 2 and 3 was either 'A-B' or 'B-A'. At the first study visit, after written informed consent was obtained, the principal investigator (TR) called the person creating the list of random numbers to obtain information on the order of the exercise experiments for visit 2 and 3, respectively. The patient was immediately informed about the testing order for the following study visits.

\section{Assessments}

All tests were scheduled at the same time of the day $(+-1 \mathrm{~h}$ deviation) to avoid any potential impact of diurnal variation on pulmonary function measurements [14]. The time period between study visit 1 and 3 was $8 \pm 2$ days, respectively. Patients were told to abstain from fatty meals (for $3 \mathrm{~h}$ ), caffeine-containing substances (for $4 \mathrm{~h}$ ) and to avoid vigorous physical exercise during the last 24-h prior to the study visits, respectively. Moreover, patients were told to abstain 


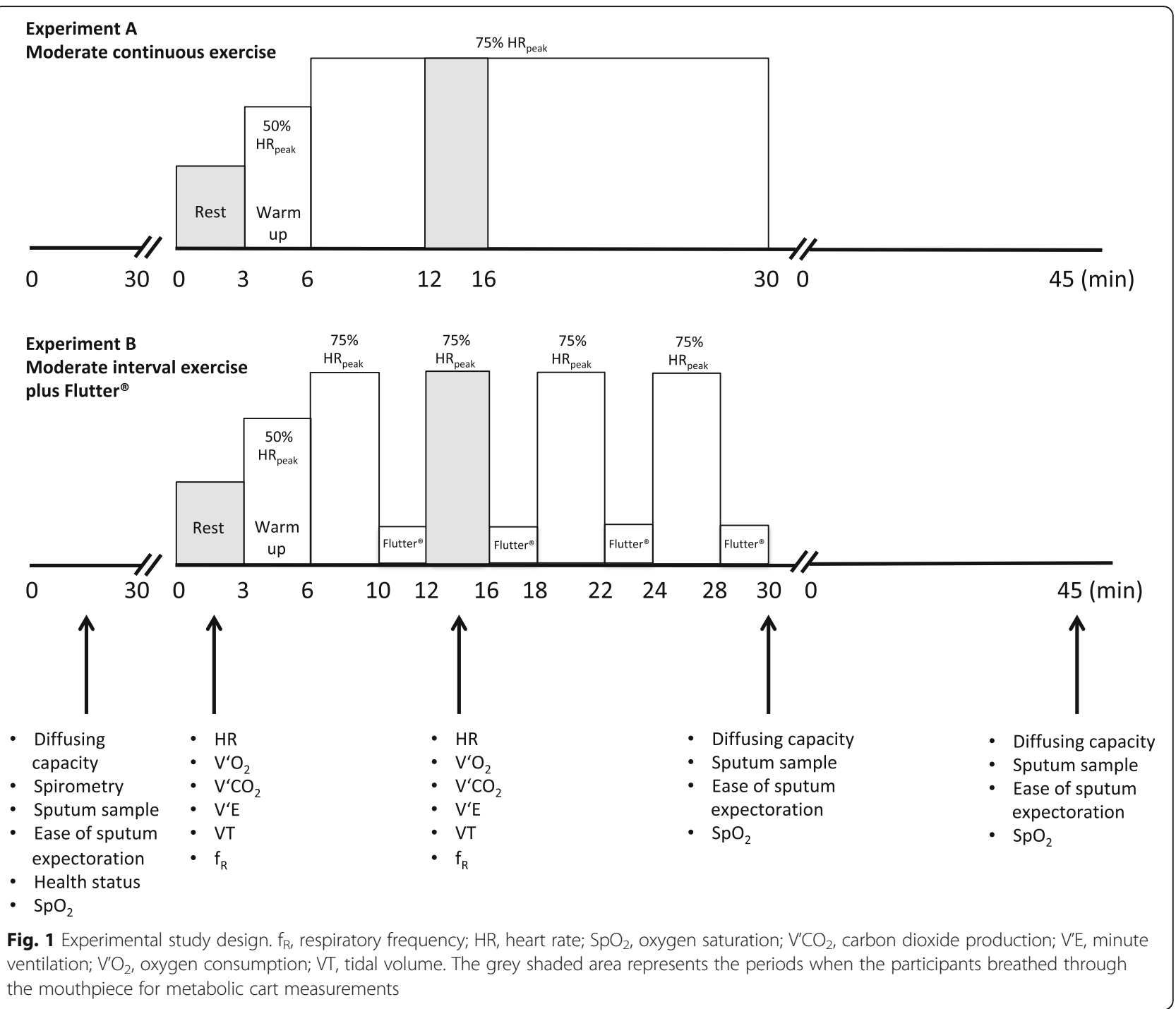

from their regular inhalation and airway clearance therapy on the day of the study visits. The following provides a short description of assessments methods.

\section{Sputum samples}

At the beginning of each study visit, one sputum sample was collected. At study visits 2 and 3, two additional samples were collected immediately post-exercise and again 45 min post-exercise, referred to as recovery (Fig. 1). Sputum was gently expectorated and collected into sterile and coded containers (cryotubes $5 \mathrm{~mL}, \mathrm{VWR}$ ). The containers were immediately stored at $-4{ }^{\circ} \mathrm{C}$ and transferred on ice into a deep freezer $\left(-80^{\circ} \mathrm{C}\right)$ after each study visit.

\section{Sputum rheology}

Rheological measurements were performed on a MCR 702 rheometer (Anton Paar, Austria) in parallel plate mode, using sandblasted $25 \mathrm{~mm}$ diameter stainless steel plates
(PP25 S Anton Paar, Austria) and a gap size of $0.5 \mathrm{~mm}$. First, a frequency sweep was performed $\left(0.1-100 \mathrm{rad} \mathrm{s}^{-1}\right.$, $\gamma=1 \%)$ followed by an amplitude sweep $(0.1-1000 \%, \omega=$ $\left.1 \mathrm{rad} \mathrm{s}^{-1}\right)$. The snap frozen sputum samples $\left(-80^{\circ} \mathrm{C}\right)$ were transferred to the fridge $\left(4{ }^{\circ} \mathrm{C}\right)$ at least $6 \mathrm{~h}$ before the measurement. The slowly thawed samples were then transferred from the cryotubes to the lower measuring plate using a $1 \mathrm{~mL}$ micropipette. The micropipette tips were cut in the front with a scalpel to have a larger die, thus minimizing shear on the sample. The upper plate was slowly lowered onto the sputum, and a solvent trap containing moist sponges was placed over the sample. Prior to measurements, the sputum was let to rest for five minutes. All measurements were performed temperature controlled at $20{ }^{\circ} \mathrm{C}$. Inertia calculations are based on equations reported by Ewoldt et al. [15].

The spinnability of sputum describes its ability to form filaments, which provides valuable information about cohesion 
forces in the sputum [16]. At the end of each rheological measurement, the upper plate was separated from the lower plate at a constant velocity of $3.6 \mathrm{~mm} \mathrm{~s}^{-1}$ [17], which was filmed (iPhone 6, Apple) at $120 \mathrm{fps}$ (Fig. 2a). The sputum formed a filament between the separating plates. The separation distance at which the sample broke ('spinnability') was extracted from the movie by counting the amount of frames from the onset of separation until filament breaking.

To estimate sputum solids content, $0.25 \mathrm{~mL}$ aliquots of sputum were filled in $1.5 \mathrm{~mL}$ HPLC vials (VWR, Switzerland) and weighed with a high precision scale (Mettler AE 163, Mettler Toledo, Switzerland). The samples were then dried for $24 \mathrm{~h}$ at $50{ }^{\circ} \mathrm{C}$ and a pressure of $100 \mathrm{mbar}$ using a vacuum drying oven (SalvisLab, Switzerland) and subsequently weighed again. All rheological measurements were done by a person $(\mathrm{PB})$ who was blinded with respect to the two different experimental conditions.

Ease of sputum expectoration was assessed on a $10 \mathrm{~cm}$ visual analogue scale $(0=$ very difficult and $10=$ very easy $)$. A blinded assessor, not involved in the study, measured the distance for all scales after completion of all study experiments.

\section{Spirometry}

Spirometry was always performed before diffusing capacity measurements with the patient in sitting position using a commercially available system (MasterScreen ${ }^{\mathrm{Tm}}$ PFT Pro, Jaeger, PanGas AG Healthcare, Switzerland) according to American Thoracic Society/European Respiratory Society Standards [18]. All tests were performed pre-bronchodilation (i.e., withheld of short-acting bronchodilators and anticholinergic drugs for at least $4 \mathrm{~h}$, long-acting bronchodilators for at least $12 \mathrm{~h}$, and once-daily, long-acting bronchodilators for at least $24 \mathrm{~h}$ ). We calculated percent-predicted values for forced expiratory volume in $1 \mathrm{~s}\left(\mathrm{FEV}_{1}\right)$ using reference equations from Quanjer et al. [19].

\section{Pulmonary diffusing capacity}

Details on the methods can be found elsewhere [20]. In brief, pulmonary diffusing capacity measurements were done in triplicate at rest and for the measurements done 45 min post-exercise (visit 2 and 3). If intra-session reproducibility criteria were not fulfilled additional measurements were performed [21]. Two maneuvers were performed immediately post-exercise (see Fig. 1 in the publication). In general, a 5 min pause was done between consecutive maneuvers to assure adequate elimination of test gas from the lungs [22]. For the analysis, we used the average value of the first two single-breaths tests for maneuvers performed at rest and $45 \mathrm{~min}$ post-exercise, when intra-session acceptability criteria were fulfilled [21]. If intra-session acceptability criteria were not fulfilled [21], the third single-breath test was considered and the average of the two highest test results was used. For the measurements immediately post-exercise (see Fig. 1 in the publication), the first test was used for statistical analysis. We calculated percent-predicted values for diffusing capacity for nitric oxide (DLNO) and carbon monoxide (DLCO), pulmonary capillary blood volume $\left(\mathrm{V}_{\text {cap }}\right)$ and the alveolar-capillary membrane diffusing capacity for carbon monoxide (DMCO) according to references equations published by Zavorsky et al. [21].

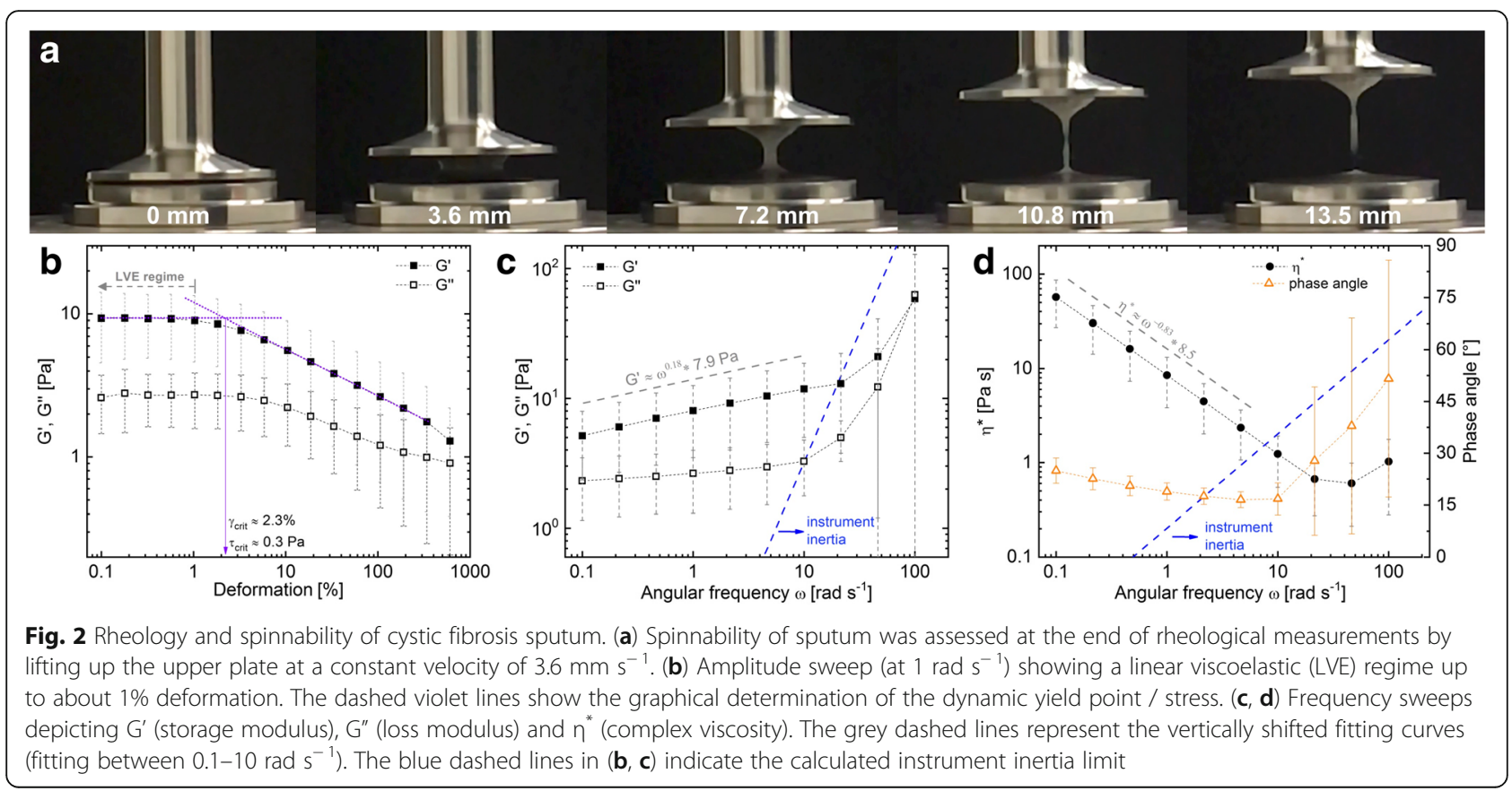




\section{Cardiopulmonary exercise testing}

Cardiopulmonary exercise testing (CPET) was performed on a cycle ergometer (custo ec 3000e, custo med $\mathrm{GmbH}$, Ottobrunn, Germany) using the Godfrey Protocol [23]. The test started with a three-minute rest period followed by three-minutes of unloaded pedaling at 60-70 rpm. Afterwards, the workrate (W, watts) was increased every minute according to the patient's height: $10 \mathrm{~W}(<120 \mathrm{~cm})$, $15 \mathrm{~W}(120-150 \mathrm{~cm})$ or $20 \mathrm{~W}(>150 \mathrm{~cm})$ [23]. The increment was individually adapted for patients with severely reduced lung function (i.e., $\mathrm{FEV}_{1}<30 \%$ predicted). After the patients had reached their maximal exercise performance, he/she rested for another three-minutes on the cycle ergometer (recovery phase).

The metabolic cart (Metalyzer ${ }^{\bullet}$ Cortex Biophysik GmbH, Leipzig, Germany) was calibrated with gases of known standard concentrations before each test. Heart rate was measured with a Polar heart rate monitor (Polar RS400, Polar Electro, Oy, Kempele, Finland) and oxygen saturation $\left(\mathrm{SpO}_{2}\right)$ was continuously measured at the earlobe (Nonin ${ }^{\circ} \mathrm{Xpod}^{\oplus}$ Pure$\mathrm{SAT}^{\oplus}$,Nonin Medical, Inc, USA). Ratings of perceived exertion and dyspnea were evaluated at peak exercise by means of a 0-10 Borg scale [24]. One of the following criteria had to be fulfilled to ensure the test was maximal: 1) plateau in oxygen consumption $\left(\mathrm{V}^{\prime} \mathrm{O}_{2}\right)$ despite an increase in workrate; 2) peak heart rate over $85 \%$ of predicted [25], 3) respiratory exchange ratio $(\mathrm{RER})>1.05,4)$ peak ventilation exceeded predicted maximum voluntary ventilation (calculated as $\mathrm{FEV}_{1} \times 35$ ) and 5) subjective impression of the supervisor. Maximal heart rates were used to calculate exercise intensities (50 and $75 \%$ of peak heart rate) for the cycling experiments at visit 2 and 3 .

\section{Patient-reported health status}

Patient-reported health status was assessed with the Feeling Thermometer. The Feeling Thermometer is part of the EQ-5D, a common instrument used for healthy economic analyses and established by the EuroQol group [26]. The Feeling Thermometer is a modified visual analogue scale in form of a thermometer. The instrument has marked intervals from 0 (worst health state ) to 100 (perfect health). We used the instrument to evaluate whether patients were in a stable health condition during the study.

\section{Anthropometry}

We measured each patient's height to the nearest $0.1 \mathrm{~cm}$ using a stadiometer (Seca). Body weight was measured to the nearest $0.5 \mathrm{~kg}$ at each study visit using a balanced scale (Seca, Model 791, Vogel \& Halke).

Moderate cycling exercise with and without Flutter ${ }^{\circledast}$ therapy At study visit 2 and 3, moderate intensity cycling exercise at $75 \%$ of the peak heart rate achieved during CPET was performed either continuously (experiment A) or in 4-min intervals (experiment B) interspersed with 2-min resting periods, during which breathing maneuvers were performed using the Flutter ${ }^{\oplus}$ (see Fig. 1). At rest and during cycling (minute 12-16'), patients respired through a mouthpiece connected to the metabolic cart to measure respiratory gases (Fig. 1). Heart rate was continuously monitored with a chest belt and heart rate monitor (Polar RS400, Polar Electro, Oy, Kempele, Finland) and $\mathrm{SpO}_{2}$ with an earlobe pulse oximeter (Nonin ${ }^{\circ}$ $\mathrm{Xpod}^{\oplus}$ PureSAT $^{\oplus}$,Nonin Medical, Inc, USA), respectively. The average value during $3 \mathrm{~min}$ at rest and during minutes 14-16 during exercise (steady-state conditions) were used for data analyses.

\section{Flutter $^{\circledast}$ breathing therapy}

The Flutter (VRP1, Eur. Patent. No: 0337990) is an airway clearance device providing oscillations during exhalation and vibrations of the airways aiming to facilitate mucus clearance in the airways. The Flutter is a pipe like device with an oscillating stainless steel ball and a perforated cover. The device produces positive expiratory pressure and the angle at which the Flutter ${ }^{\odot}$ is held determines the oscillation frequency of 6 to $20 \mathrm{~Hz}$ [27]. Exhalation through the Flutter ${ }^{\circ}$ causes oscillation of the steel ball and produces rhythmic variations in positive expiratory pressure of 10 to $25 \mathrm{~cm} \mathrm{H}_{2} \mathrm{O}[28,29]$. Flutter ${ }^{\bullet}$ therapy increases peak expiratory flow and creates an expiratory airflow bias in CF [6], initiating mucociliary clearance mechanisms.

During experiment B, 6-10 breathing maneuvers were performed during each of the 2 min resting periods (Fig. 1) without forced expiratory technique. The breathing maneuvers started with a slightly deep inspiration, a 2-3 s end-inspiratory pause and a forced expiration lasting about $5 \mathrm{~s}$ while the patient was sitting on the cycle ergometer without pedaling. The Flutter ${ }^{\circledR}$ device was kept in neutral (horizontal) position to maximize the oscillation amplitude and to target a frequency range of $10-15 \mathrm{~Hz}$ [29], optimal for mucus clearance. All patients received proper instructions on the use of the device at the first study visit. Patients without experience with the Flutter ${ }^{\ominus}$ received a device at the end of visit 1 enabling practice at home before the second study visit.

\section{Statistical analysis and sample size calculation}

All statistical analyses were performed with the statistical software package SPSS version 23 (IBM Corp. Armont, NY, USA). Descriptive data are presented as median (interquartile range, IQR), mean $\pm \mathrm{SD}$ or $\mathrm{N}(\%)$. We used the non-parametric Friedman Test to test for differences in resting (pre-exercise) sputum properties, spirometry, pulmonary diffusing capacity and patient-reported health status between the three study visits. Differences in outcome variables between the three different time points (pre-exercise; immediately post-exercise and $45 \mathrm{~min}$ 
post-exercise, respectively) during each experimental condition were analyzed with the non-parametric Friedman test followed by a Wilcoxon-signed rank test, if changes over time in the Friedman test were significant $(P<0.05)$. We calculated absolute changes between the different time-points (i.e., post-exercise minus pre-exercise and 45 min post-exercise minus pre-exercise values) and compared the two experimental conditions using the non-parametric Mann-Whitney-U test. The level of statistical significance was set as $P<0.05$.

No previous study has investigated changes in sputum viscoelasticity following a combination of cycling and Flutter ${ }^{\ominus}$ using the same instruments as in our study from which we could derive means and standard deviations (SD's) and on which we could base our power calculations. However, two previous studies using randomized crossover designs comparing i) an acute bout of cycling and treadmill exercise versus no exercise [11] or ii) Flutter $^{\bullet}$ therapy with autogenic drainage [7] were able to demonstrate significant changes in sputum viscoelasticity in 14 individuals with CF in each study. We therefore aimed to include 16 patients in our study.

\section{Results}

Baseline patient characteristics are shown in Table 1 $(N=16)$.

During the study, one female patient requiring oral antibiotic therapy for treatment of a pulmonary exacerbation and was excluded from the analyses. All other patients completed all assessments without complications. There

Table 1 Patient baseline characteristics

\begin{tabular}{|c|c|}
\hline \multicolumn{2}{|l|}{ Variables } \\
\hline N & 16 \\
\hline Sex (male/female) & $7 / 9$ \\
\hline Age (years) & $23(22,25)$ \\
\hline BMI $\left(\mathrm{kg} \mathrm{m}^{-2}\right)$ & $20(18,21)$ \\
\hline Cystic fibrosis-related diabetes (N (\%)) & $8(50)$ \\
\hline Pancreatic insufficiency ( $N(\%))$ & $13(81)$ \\
\hline Chronic Pseudomonas aeruginosa infection (N (\%)) & $7(44)$ \\
\hline $\mathrm{FEV}_{1}(\%$ predicted) & $52(43,72)$ \\
\hline DLNO (\% predicted) & $59(51,73)$ \\
\hline DLCO (\% predicted) & $82(69,86)$ \\
\hline$V^{\prime} \mathrm{O}_{2 \text { peak }}\left(\mathrm{mL} \mathrm{kg}{ }^{-1} \mathrm{~min}^{-1}\right)$ & $32.0(30.3,34.4)$ \\
\hline Mechanical power $\left(\mathrm{W} \mathrm{kg}^{-1}\right)$ & $2.9(2.3,3.1)$ \\
\hline $\mathrm{HR}_{\text {peak }}$ (beats $\mathrm{min}^{-1}$ ) & $167(163,179)$ \\
\hline RER & $1.20(1.15,1.26)$ \\
\hline
\end{tabular}

Data are median (IQR) or N (\%). BMI body mass index, CF cystic fibrosis, DLCO diffusing capacity of the lung for carbon monoxide, DLNO diffusing capacity of the lung for nitric oxide, $F E V_{1}$ forced expiratory volume in one second, $H R_{\text {peak }}$ peak heart rate, $R E R$ respiratory exchange ratio, $V^{\prime} O_{2 p e a k}$ peak oxygen consumption were no differences in pre-exercise sputum properties, pulmonary function data and patient-reported health status between the three study visits, respectively (Additional file 1 : Table S1). Cardiorespiratory variables during exercise were comparable between both experiments (Additional file 2: Table S2), whereas patients had a higher respiratory frequency during experiment A compared to $\mathrm{B}(P<0.001)$.

All patients were able to provide sputum samples at the requested time points during the study. 13/15 patients had previous experience using Flutter ${ }^{\circ}$, but only two were using the Flutter ${ }^{\circ}$ on a regular basis.

\section{CF sputum viscoelasticity and spinnability}

The average of all sputum samples $(n=45)$ obtained at rest during each of the three visits showed spinnability (Fig. 2a) and viscoelastic behavior (Fig. 2b-d) characteristic for CF sputum [7, 30-32]. Details can be found in the online supplements (Additional file 3: Table S4). At high frequencies $\left(\omega>10 \mathrm{rad} \mathrm{s}^{-1}\right) \mathrm{G}^{\prime}$ and G" as well as $\eta "$ (complex viscosity) and the phase angle increased due to instrument inertia, which causes artifacts in the sample signal. Consequently, the analysis of sputum viscoelasticity (G' and G') was restricted to an angular frequency of $10 \mathrm{rad} \mathrm{s}^{-1}$. Instrument inertia is further debated in the Discussion section and online supplements.

\section{Changes in sputum rheological properties}

Table 2 shows changes in sputum properties for each experimental condition. No time-course changes were found during either experiment $\mathrm{A}$ or $\mathrm{B}$, except for sputum solids content during experimental condition A $(P=0.038)$. Individual raw data for $\mathrm{G}^{\prime}$ at 1 and $10 \mathrm{rad} \mathrm{s}^{-1}$ are shown in Additional file 4: Figure S1 and Additional file 5: Figure S2 in the online supplements. In the experimental condition A, one study participant had very high values for $G$ ' at 1 and $10 \mathrm{rad} \mathrm{s}^{-1}$ immediately post-exercise. Of note, there was no technical problem during the rheological measurements, but the sputum sample was purulent and thick. A summary of all sputum rheological data excluding this particular participant is shown in Additional file 6: Table S3 in the online supplements.

No differences in sputum rheological properties (viscoelastic moduli G' and G", yield stress, solids content) were found between experiments (Table 3), except differences in sputum spinnability comparing pre- versus $45^{\prime}$ post-exercise values between experiments. During recovery (absolute change, pre- vs. 45 min post-exercise), we noticed differences in patient reported ease of sputum expectoration, favoring experimental condition A $(P=0.016)$.

\section{Changes in pulmonary diffusing capacity}

Individual raw data for $D \mathrm{LNO}, D \mathrm{LCO}, \mathrm{V}_{\mathrm{A}}$ and $\mathrm{V}_{\text {cap }}$ at different time points during experiments $\mathrm{A}$ and $\mathrm{B}$ are 


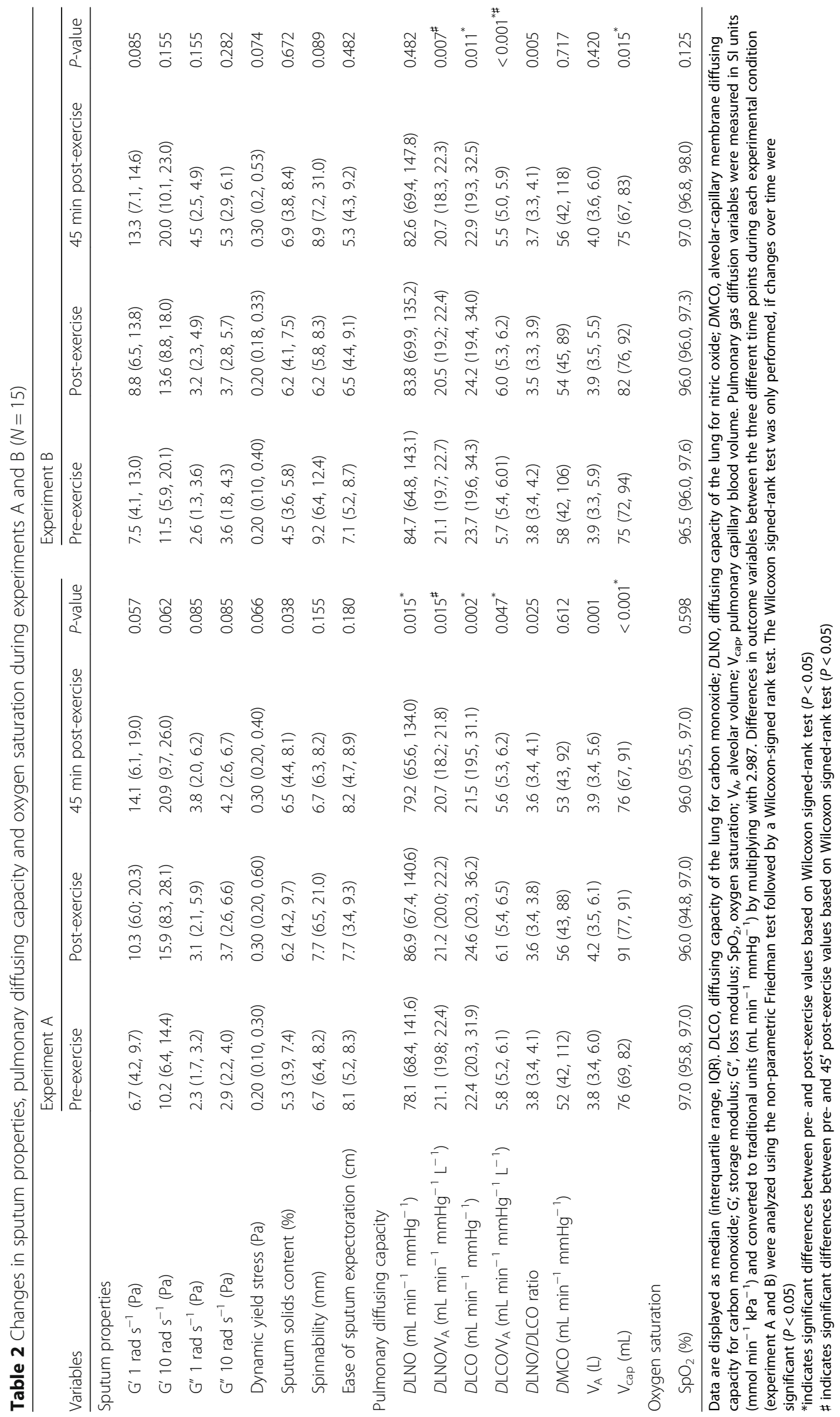




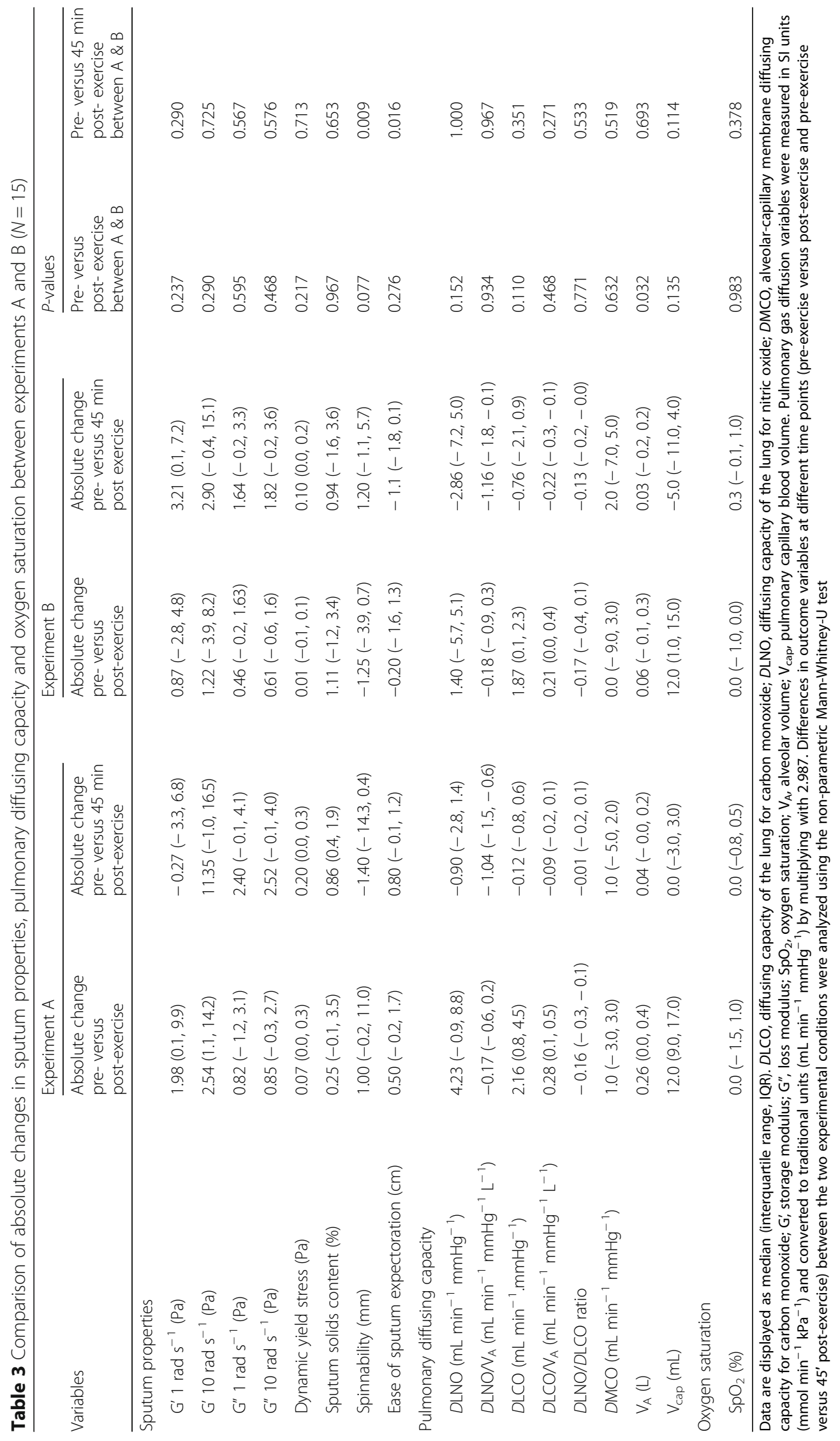


shown in Additional file 7: Figure S3 and Additional file 8: Figure S4 in the online supplements. Time course changes in pulmonary diffusing capacity were observed during both experiments, while changes in $D \mathrm{LNO}$ and $\mathrm{V}_{\mathrm{A}}$ were only observed in experimental condition A (Table 2). No differences in pulmonary diffusing capacity were found between the two experimental conditions (Table 3), except a higher $\mathrm{V}_{\mathrm{A}}$ comparing post-exercise and pre-exercise changes favoring experiment $\mathrm{A}(P=0.032)$.

\section{Discussion}

This randomized controlled crossover study investigated acute effects of moderate intensity continuous cycling exercise versus interval cycling exercise incorporating the Flutter ${ }^{\circ}$ device on sputum viscoelasticity (primary endpoint) and pulmonary diffusing capacity in adults with CF. This study provides three important findings. First, the addition of Flutter ${ }^{\odot}$ to moderately intense stationary cycling has no measurable effect on sputum viscoelastic properties compared to stationary cycling alone. Second, our results highlight experimental challenges to simulate 'coughing' (i.e., $100 \mathrm{rad} \mathrm{s}^{-1}$ measurements or generally high frequency measurements) in a shear rheological setup due to instrument inertia effects. Third, the increase in pulmonary diffusing capacity over time reflects an acute exercise-induced effect, not sustained post-exercise.

\section{Sputum rheological properties and exercise}

In the present study, we found no differences in sputum viscoelasticity between the two experimental conditions, thus rejecting our initial hypothesis. Two previous studies reported altered sputum viscoelasticity after an acute bout of treadmill exercise or Flutter ${ }^{\circ}$ and treadmill exercise compared to resting breathing in adults with CF $[6,11]$. Treadmill but not cycling exercise reduced sputum viscoelasticity and trunk oscillations during treadmill running/walking have been postulated as a possible underlying mechanism [11]. One could argue that the chosen exercise mode in our study was not sufficient to improve viscoelastic properties of sputum in our patients and/or that the magnitude of effect from Flutter ${ }^{\oplus}$ was not large enough to produce greater changes in sputum viscoelastic properties compared to cycling alone. During exercise, our patients achieved approximately $47-49 \%$ of their maximal minute ventilation (90-97\% of their maximal tidal volumes and $50-55 \%$ of their maximal respiratory frequencies, see Additional file 2: Table S2) suggestive of a high ventilatory demand. Higher exercise intensities (e.g., 90\% of maximal heart rate) may induce significant airway narrowing [12] unlikely to be maintained by many patients when exercising for longer periods, in particular, in patients with advanced lung disease. With respect to Flutter, our patients performed 6-10 breathing maneuvers during each of four cycles. Higher volumes of
Flutter therapy (6 cycles à 15 breaths) combined with huffing and coughing (forced expiration technique, FET) improved sputum viscoelasticity compared to resting breathing in adults with CF [6]. It is important to note that we deliberately did not follow existing CF physiotherapy recommendations [27] suggesting to individually determine the angle of the Flutter ${ }^{\circ}$ along with the performance of forced expiratory maneuvers. In this study, we were mainly interested in mechanistic effects of airway oscillations on sputum viscoelasticity [7] on top of high ventilation during exercise. We did not implement forced expiratory maneuvers due to potential interference with our cycling protocol and pulmonary gas exchange measurements. The authors hypothesize that a more intense Flutter ${ }^{\circ}$ therapy, together with individual adaptation of the Flutter angle, but not the lack of forced expiratory maneuvers, could explain the absence of additional effect in our study. Given the fact that positive expiratory pressure and oscillations are thought to mechanically impact on biophysical properties of mucus (i.e., reduction of viscoelasticity), huffing and coughing following Flutter maneuvers assist in mobilization and transport of secretions from peripheral to central airways, but should not substantially change viscoelastic properties of sputum in addition. This hypothesis is supported by an in vitro experiment demonstrating that Flutter oscillations alone augment sputum elasticity after 15 and $30 \mathrm{~min}$, respectively [7].

It is important to mention that in comparison to our experimental study design, the study by Dwyer et al. [6] compared Flutter therapy with resting breathing (no intervention), which likely increases the chance to observe effects between experimental conditions. Nevertheless, given the high variability of sputum properties [33] and differing intraand interindividual responses to airway clearance therapy, a "no intervention" visit would have probably provided further insights into within-patient treatment responses.

Interestingly, and in line with findings by Dwyer et al. [11], ease of sputum expectoration was higher during recovery from continuous cycling versus cycling exercise with Flutter ${ }^{\circ}$. This suggests that patients perceive the benefit of airway clearance therapy not immediately but during recovery from exercise. However, the clinical meaningfulness of these findings cannot be interpreted due to the lack of a minimal important difference for the visual analogue scale.

\section{Rheological measurements and inertia}

We observed occurrence of inertia at high frequencies, causing experimental artifacts (see Additional file 9 for further discussion). King and Macklem suggested first that sputum rheology at high frequency simulates cough studying dog tracheal mucus [34]. The concept was then further elaborated suggesting that low frequency $\left(1 \mathrm{rad} \mathrm{s}^{-1}\right)$ deformations are relevant when simulating ciliary transport [35] whereas high frequency (100 $\left.\mathrm{rad} \mathrm{s}^{-1}\right)$ 
deformations are more characteristic for cough clearance [36]. The $1 \mathrm{rad} \mathrm{s}^{-1} / 100 \mathrm{rad} \mathrm{s}^{-1}$ concept was initially elaborated using active microrheology but was later applied in shear rheology testing $[6,11,37,38]$. We found a strong increase in moduli (G, G") and phase angles at frequencies $>10 \mathrm{rad} \mathrm{s}^{-1}$ (Fig. 2c and $\mathrm{d}$, Additional file 10: Figure S5a) and observed that sample torques deviated from the electrical torques (Additional file 10: Figure S5b), both strong indicators for inertia. The deviation of sample torque from electrical torque due to inertia is schematically represented in torque vector drawings in Additional file 10: Figure S5c. Also, we calculated the theoretical inertia limit of the rheometer, which agreed well with the observed onset of inertia. Further proof is obtained comparing our results to other findings that show a continuous trend of the dynamic moduli up to $50 \mathrm{~Hz}\left(\approx 314 \mathrm{rad} \mathrm{s}^{-1}\right)$ using passive microrheology [32], which is not affected by inertia at frequencies below $1 \mathrm{MHz}$ [39]. Data generated in previous studies using shear rheology at $100 \mathrm{rad} \mathrm{s}^{-1}$ also showed signs of inertia $[6,11,37,38]$, revealed by a substantially increased loss modulus $G^{\prime \prime}$ or complex modulus $\left(G^{*}\right)$ and high $\tan \delta$ values compared to those measured at $1 \mathrm{rad} \mathrm{s}^{-1}$. Future rheology measurements with sputum should be carefully checked for inertia, as in the worst-case scenario, false positive or false negative outcomes occur. We propose restricting frequencies to $10 \mathrm{rad} \mathrm{s}^{-1}$ to simulate the high frequency behavior of sputum in shear rheology.

\section{Pulmonary diffusing capacity and exercise}

In the present study, DLNO and DLCO increased during continuous cycling exercise, whereas interval cycling exercise interspersed with use of the Flutter increased only DLCO but not $D L N O$, most likely due to the absence of increase in $\mathrm{V}_{\mathrm{A}}$. It is well known that $D \mathrm{LNO}, D \mathrm{LCO}$, and $\mathrm{V}_{\text {cap }}$ increase linearly during exercise with respect to cardiac output [40]. In our study, continuous cycling increased post-exercise DLNO by about $5 \%$, but the effect was not sustained during recovery. We extend previous findings reporting a remarkable increase in DLNO (39 $\pm 8 \%$ from rest using rebreathing measurements) during moderate intensity cycling exercise in $\mathrm{CF}$ adults, with the authors questioning the duration of beneficial effects [12]. Our data demonstrate that increase in DLNO is (only) an acute, exercise-induced effect, most likely the result of increased $V_{A}$ and subsequently greater surface area for diffusion rather than improved mucociliary clearance mechanisms such as improved sputum hydration and/or viscoelastic properties.

This study has limitations. First, we did not measure expiratory flow during exercise $[6,11]$ to evaluate whether our experiments were sufficient to create an expiratory airflow bias, a mechanism potentially improving mucociliary clearance. Furthermore, the sputum was sheared at $50 \mathrm{~Pa}$ in simple shear experiments prior to spinnability measurements. The shear homogenized the samples, theoretically disrupting sputum microstructure, which could have caused the comparably low spinnability values. Finally, our study patient cohort was small, limiting the generalizability of our findings to the overall CF population.

\section{Conclusions}

We conclude that the addition of Flutter ${ }^{\circledR}$ to moderate intensity interval cycling exercise has no measurable effect on the viscoelastic properties of sputum compared to moderate intensity continuous cycling alone. The higher pulmonary diffusing capacity represents an acute exercise-induced effect not sustained post-exercise.

\section{Additional files}

Additional file 1: Table S1. Pre-exercise sputum properties, pulmonary function data and patient-reported health status at each study visit $(N=15)$. (DOCX $27 \mathrm{~kb}$ )

Additional file 2: Table S2. Comparison of cardiorespiratory variables at rest and exercise between the two experimental conditions $(N=15)$. (DOCX $22 \mathrm{~kb}$ )

Additional file 3: Table S4. Derived viscoelastic parameters from cystic fibrosis sputum at rest. (DOCX $23 \mathrm{~kb}$ )

Additional file 4: Figure S1. Comparison of individual raw data for G' (storage modulus) at 1 and 10 rad. $\mathrm{s}^{-1}$ at different time points during experiment $A$ and experiment $B(N=15)$. (DOCX $432 \mathrm{~kb})$

Additional file 5: Figure S2. Comparison of individual raw data for $\mathrm{G}^{\prime}$ (storage modulus) at 1 and 10 rad.s s $^{-1}$ at different time points during experiment $A$ and experiment $B(N=14$, excluding the outlier). (DOCX 453 kb)

Additional file 6: Table S3. Changes in sputum rheological properties during experiments $A$ and $B$ without one extreme outlier $(N=14)$. (DOCX $25 \mathrm{~kb}$ )

Additional file 7: Figure S3. Comparison of individual raw data for $D L N O$ and $D L C O$ at different time points during experiment $A$ and experiment $B(N=15)$. (DOCX $468 \mathrm{~kb})$

Additional file 8: Figure S4. Comparison of individual raw data for alveolar volume $\left(V_{A}\right)$ and $V_{\text {cap }}$ at different time points during experiment A and experiment $B(N=15)$. (DOCX $1406 \mathrm{~kb})$

Additional file 9: Instrument inertia causes artifacts in shear rheology measurements at high frequencies. (DOCX 29 kb)

Additional file 10: Figure S5. Instrument inertia in cystic fibrosis sputum shear rheology measurements (DOCX 978 kb)

\begin{abstract}
Abbreviations
ACT: airway clearance techniques; BMl: body mass index; CF: cystic fibrosis; CPET: cardiopulmonary exercise testing; DLCO: pulmonary diffusing capacity for carbon monoxide; DLNO: pulmonary diffusing capacity for nitric oxide; DLNO/DLCO ratio: ratio of pulmonary diffusing capacity for nitric oxide to pulmonary diffusing capacity for carbon monoxide; DMCO: alveolar-capillary membrane diffusing capacity for carbon monoxide; $F E V_{1}$ : forced expiratory volume in $1 \mathrm{~s}$; $\mathrm{f}_{\mathrm{R}}$ : respiratory frequency; $\mathrm{G}^{*}$ : complex modulus; $\mathrm{G}^{\prime}$ : storage modulus; G": loss modulus; HR: heart rate; LVE: linear viscoelasticity; PEP: positive expiratory pressure; RER: respiratory exchange ratio; $\mathrm{SpO}_{2}$ : oxygen saturation; $\tan \delta$ : loss tangent; $V^{\prime} \mathrm{E}$ : minute ventilation; $V^{\prime} \mathrm{O}_{2 \text { peak: }}$ peak oxygen consumption; $V_{\mathrm{A}}$ : alveolar volume; $V_{\text {cap }}$ : pulmonary capillary blood volume; VT: tidal volume; $\eta^{*}$ : complex viscosity
\end{abstract}

\section{Acknowledgments}

We kindly thank André Königs from the University Hospital Zurich for his assistance in patient recruitment; Dario Kohlbrenner from the University Hospital Zurich for measuring the visual analogue scales; Simeon Zürcher for 
his support with the randomization and Dr. Julia Braun for statistical support (both University of Zurich). Moreover, we thank Evangelia Daviskas from the Department of Respiratory Medicine, Royal Prince Hospital Alfred Hospital, Sydney, Australia, for her advice with respect to the preparation of the sputum measurements and sample handling prior to the start of this study. The authors express their appreciation to Jörg Läuger from Anton Paar for his assistance with the interpretation of the inertia effects.

\section{Funding}

The Swiss Cystic Fibrosis Society (CFCH) funded the study. The sponsor had no role in the design of the study, data collection, analysis and interpretation, or the content of the manuscript.

\section{Availability of data and materials}

The datasets used and/or analysed during the current study are available from the corresponding author on reasonable request.

\section{Authors' contributions}

TR takes responsibility for the overall content as guarantor. TR, SK, and HD contributed to the study design. TR and MMB conducted all experiments. $L B$, $\mathrm{PB}$ and $\mathrm{PF}$ were responsible for the sputum analysis. $\mathrm{LB}$ and $\mathrm{PB}$ measured and analyzed all sputum samples and were blinded to the patient's characteristics and experimental conditions. TR performed the data analysis. All authors contributed to the data interpretation and writing of the manuscript. TR wrote the first manuscript draft, all authors revised and approved the final manuscript version.

\section{Ethics approval and consent to participate}

Ethical approval was obtained from the Cantonal Ethics Committee of Zurich (2015-00153), Switzerland. All patients provided written informed consent.

\section{Competing interests}

The authors declare that they have no competing interests.

\section{Publisher's Note}

Springer Nature remains neutral with regard to jurisdictional claims in published maps and institutional affiliations.

\section{Author details}

${ }^{1}$ Epidemiology, Biostatistics and Prevention Institute (EBPI), University of Zurich, Zurich, Switzerland. ${ }^{2}$ Division of Occupational and Environmental Medicine, University of Zurich and University Hospital Zurich, Zurich, Switzerland. ${ }^{3}$ Department of Health Science and Technology, ETH Zurich, Zurich, Switzerland. ${ }^{4}$ Division of Pulmonology, University Hospital of Zurich, Zurich, Switzerland.

\section{Received: 22 February 2018 Accepted: 24 May 2018}

Published online: 14 June 2018

\section{References}

1. Boucher RC. New concepts of the pathogenesis of cystic fibrosis lung disease. Eur Respir J. 2004;23:146-58.

2. Rowbotham NJ, Smith S, Leighton PA, Rayner OC, Gathercole K, Elliott ZC, Nash EF, Daniels T, Duff AJA, Collins S, Chandran S, Peaple U, Hurley MN, Brownlee K, Smyth AR. The top 10 research priorities in cystic fibrosis developed by a partnership between people with CF and healthcare providers. Thorax. 2018;73:388-90.

3. Morrison L, Innes S. Oscillating devices for airway clearance in people with cystic fibrosis. Cochrane Database Syst Rev. 2017:5:CD006842

4. McCarren B, Alison JA. Physiological effects of vibration in subjects with cystic fibrosis. Eur Respir J. 2006;27:1204-9.

5. Konstan MW, Stern RC, Doershuk CF. Efficacy of the flutter device for airway mucus clearance in patients with cystic fibrosis. J Pediatr. 1994:124:689-93.

6. Dwyer TJ, Zainuldin R, Daviskas E, Bye PT, Alison JA. Effects of treadmill exercise versus flutter(R) on respiratory flow and sputum properties in adults with cystic fibrosis: a randomised, controlled, cross-over trial. BMC Pulm Med. 2017;17:14.

7. App EM, Kieselmann R, Reinhardt D, Lindemann H, Dasgupta B, King M, Brand P. Sputum rheology changes in cystic fibrosis lung disease following two different types of physiotherapy: flutter vs autogenic drainage. Chest. 1998;114:171-7.
8. Reix P, Aubert F, Werck-Gallois MC, Toutain A, Mazzocchi C, Moreux N, Bellon $\mathrm{G}$, Rabilloud M, Kassai B. Exercise with incorporated expiratory manoeuvres was as effective as breathing techniques for airway clearance in children with cystic fibrosis: a randomised crossover trial. J Phys. 2012;58:241-7.

9. Basser PJ, McMahon TA, Griffith P. The mechanism of mucus clearance in cough. J Biomech Eng. 1989;111:288-97.

10. Hebestreit A, Kersting U, Basler B, Jeschke R, Hebestreit $H$. Exercise inhibits epithelial sodium channels in patients with cystic fibrosis. Am J Respir Crit Care Med. 2001;164:443-6.

11. Dwyer TJ, Alison JA, McKeough ZJ, Daviskas E, Bye PT. Effects of exercise on respiratory flow and sputum properties in patients with cystic fibrosis. Chest. 2011;139:870-7.

12. Wheatley CM, Baker SE, Morgan MA, Martinez MG, Liu B, Rowe SM, Morgan WJ, Wong EC, Karpen SR, Snyder EM. Moderate intensity exercise mediates comparable increases in exhaled chloride as albuterol in individuals with cystic fibrosis. Respir Med. 2015;109:1001-11.

13. Fuchs HJ, Borowitz DS, Christiansen DH, Morris EM, Nash ML, Ramsey BW Rosenstein BJ, Smith AL, Wohl ME. Effect of aerosolized recombinant human DNase on exacerbations of respiratory symptoms and on pulmonary function in patients with cystic fibrosis. The Pulmozyme Study Group N Eng J Med. 1994:331:637-42.

14. Cinkotai FF, Thomson ML. Diurnal variation in pulmonary diffusing capacity for carbon monoxide. J Appl Physiol. 1966;21:539-42.

15. Ewoldt RH, Johnston MT, Caretta LM. Experimental challenges of shear rheology: how to avoid bad data. Biol Med Phys Biomed. 2015:207-41.

16. Burnett J, Glover FA, Blair GW. Field measurements of the "spinability" of bovine cervical mucus. Biorheology. 1967;4:41-5.

17. Critchfield AS, Yao G, Jaishankar A, Friedlander RS, Lieleg O, Doyle PS, McKinley G, House M, Ribbeck K. Cervical mucus properties stratify risk for preterm birth. PLoS One. 2013;8:e69528.

18. Miller MR, Hankinson J, Brusasco V, Burgos F, Casaburi R, Coates A, Crapo R, Enright $P$, van der Grinten $C P$, Gustafsson $P$, Jensen $R$, Johnson DC, Maclntyre N, McKay R, Navajas D, Pedersen OF, Pellegrino R, Viegi G, Wanger J. Standardisation of spirometry. Eur Respir J 2005;26:319-338.

19. Quanjer PH, Stanojevic S, Cole TJ, Baur X, Hall GL, Culver BH, Enright PL, Hankinson JL, Ip MS, Zheng J, Stocks J. Multi-ethnic reference values for spirometry for the 3-95-yr age range: the global lung function 2012 equations. Eur Respir J. 2012:40:1324-43.

20. Radtke T, Benden C, Maggi-Beba M, Kriemler S, van der Lee I, Dressel H. Intrasession and inter-session variability of nitric oxide pulmonary diffusing capacity in adults with cystic fibrosis. Respir Physiol Neurobiol. 2017;246:33-8.

21. Zavorsky GS, Hsia CC, Hughes JM, Borland CD, Guenard H, van der Lee I, Steenbruggen I, Naeije R, Cao J, Dinh-Xuan AT. Standardisation and application of the single-breath determination of nitric oxide uptake in the lung. Eur Respir J. 2017;49

22. Macintyre N, Crapo RO, Viegi G, Johnson DC, van der Grinten CP, Brusasco V, Burgos F, Casaburi R, Coates A, Enright P, Gustafsson P, Hankinson J, Jensen R, McKay R, Miller MR, Navajas D, Pedersen OF, Pellegrino R, Wanger $J$. Standardisation of the single-breath determination of carbon monoxide uptake in the lung. Eur Respir J 2005;26:720-735

23. Godfrey S, Mearns M. Pulmonary function and response to exercise in cystic fibrosis. Arch Dis Child. 1971;46:144-51.

24. Borg GA. Psychophysical bases of perceived exertion. Med Sci Sports Exerc. 1982;14:377-81.

25. Balady GJ, Arena R, Sietsema K, Myers J, Coke L, Fletcher GF, Forman D, Franklin B, Guazzi M, Gulati M, Keteyian SJ, Lavie CJ, Macko R, Mancini D, Milani RV. Clinician's guide to cardiopulmonary exercise testing in adults: a scientific statement from the American Heart Association. Circulation. 2010;122:191-225

26. EuroQol G. EuroQol-a new facility for the measurement of health-related quality of life. Health Policy. 1990;16:199-208.

27. International Physiotherapy Group for Cystic Fibrosis. Physiotherapy for people with cystic fibrosis: from infant to adult. 4th edition. 2009. Available online: https://www.cfww.org/docs/ipg-cf/bluebook/ bluebooklet2009websiteversion.pdf accessed at April $27^{\text {th }} 2018$.

28. Homnick DN, Anderson K, Marks JH. Comparison of the flutter device to standard chest physiotherapy in hospitalized patients with cystic fibrosis - a pilot study. Chest. 1998;114:993-7.

29. Volsko TA, DiFiore J, Chatburn RL. Performance comparison of two oscillating positive expiratory pressure devices: acapella versus flutter. Respir Care. 2003:48:124-30 
30. Serisier DJ, Carroll MP, Shute JK, Young SA. Macrorheology of cystic fibrosis, chronic obstructive pulmonary disease \& normal sputum. Respir Res. 2009;10:63.

31. Tomaiuolo G, Rusciano G, Caserta S, Carciati A, Carnovale V, Abete P, Sasso A, Guido S. A new method to improve the clinical evaluation of cystic fibrosis patients by mucus viscoelastic properties. PLoS One. 2014;9:e82297.

32. Hill DB, Vasquez PA, Mellnik J, McKinley SA, Vose A, Mu F, Henderson AG, Donaldson SH, Alexis NE, Boucher RC, Forest MG. A biophysical basis for mucus solids concentration as a candidate biomarker for airways disease. PLoS One. 2014;9

33. Radtke T, Böni L, Bohnacker P, Fischer P, Benden C, Dressel H. The many ways sputum flows - dealing with high within-subject variability in cystic fibrosis sputum rheology. Respir Physiol Neurobiol. 2018;254:36-9.

34. King M, Macklem PT. Rheological properties of microliter quantities of normal mucus. J Appl Physiol Respir Environ Exerc Physiol. 1977:42:797-802.

35. King M. Relationship between mucus viscoelasticity and ciliary transport in Guaran gel-frog palate model system. Biorheology. 1980;17:249-54.

36. King M. The role of mucus viscoelasticity in cough clearance. Biorheology. 1987;24:589-97.

37. Daviskas E, Anderson SD, Gomes K, Briffa P, Cochrane B, Chan HK, Young IH, Rubin BK. Inhaled mannitol for the treatment of mucociliary dysfunction in patients with bronchiectasis: effect on lung function, health status and sputum. Respirology. 2005;10:46-56.

38. Daviskas E, Anderson SD, Jaques A, Charlton B. Inhaled mannitol improves the hydration and surface properties of sputum in patients with cystic fibrosis. Chest. 2010;137:861-8.

39. Schnurr B, Gittes F, MacKintosh FC, Schmidt CF. Determining microscopic viscoelasticity in flexible and semiflexible polymer networks from thermal fluctuations. Macromolecules. 1997;30:7781-92.

40. Hsia CC. Recruitment of lung diffusing capacity: update of concept and application. Chest. 2002;122:1774-83.

\section{Ready to submit your research? Choose BMC and benefit from:}

- fast, convenient online submission

- thorough peer review by experienced researchers in your field

- rapid publication on acceptance

- support for research data, including large and complex data types

- gold Open Access which fosters wider collaboration and increased citations

- maximum visibility for your research: over $100 \mathrm{M}$ website views per year

At BMC, research is always in progress.

Learn more biomedcentral.com/submissions 